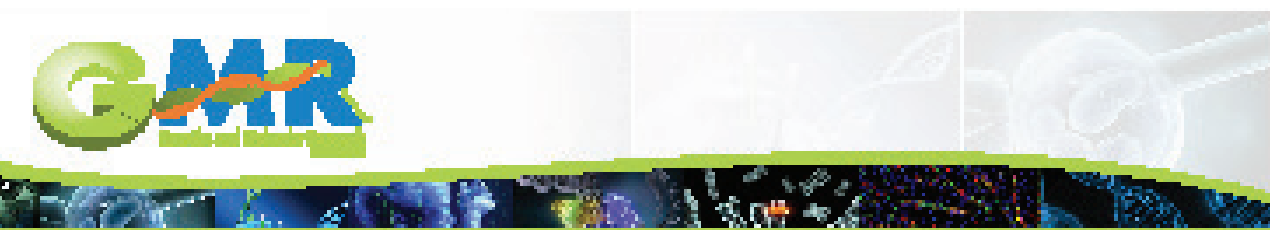

\title{
Serum levels of S-100 $\beta$ correlate with the clinical status and severity of hypoxic-ischemic encephalopathy in neonates
}

\author{
L.H. Shi ${ }^{1}$, Y. Zhou ${ }^{2}$, M.F. Guo ${ }^{1}$, J.S. Liu ${ }^{1}$, C.X. Li ${ }^{1}$, G.F. Wang ${ }^{1}$, W. Liu ${ }^{1}$ and
} L. $\operatorname{Tian}^{3}$

${ }^{1}$ Key Laboratory of Pediatric Blood Diseases, Children's Hospital of Zhengzhou, Zhengzhou, China

${ }^{2}$ Nuclear Medicine Department, Children's Hospital of Zhengzhou, Zhengzhou, China ${ }^{3}$ Department of Pediatric Hematology and Oncology, Children's Hospital of Zhengzhou, Zhengzhou, China

Corresponding authors: W. Liu / L. Tian

E-mail: liuwei107@yeah.net / tianliang0826@163.com

Genet. Mol. Res. 14 (4): 14760-14771 (2015)

Received July 6, 2015

Accepted September 26, 2015

Published November 18, 2015

DOI http://dx.doi.org/10.4238/2015.November.18.41

\begin{abstract}
The clinical significance of serum S-100 $\beta$ levels in neonates with hypoxic-ischemic encephalopathy (HIE), as a reference index to assess HIE severity, was evaluated in this study. On the basis of our strict inclusion and exclusion criteria, relevant high-quality case-control studies reporting the association between HIE and S-100 $\beta$ protein were selected from electronic database searches. The STATA version 12.0 software was used for the statistical analyses. The database search initially retrieved 93 studies (37 in English and 56 in Chinese), and following a multistep screening process, 13 high-quality studies were eventually included in our meta-analysis. The 13 case-control studies included a total of 646 HIE neonates and 381 healthy controls. The results of this meta-analysis revealed that serum S-100 $\beta$ levels in mild, moderate, and severe HIE
\end{abstract}


neonates were significantly higher than those in healthy controls, and the differences were statistically significant. Importantly, the serum S-100 $\beta$ levels increased incrementally with HIE severity. Our results support the hypothesis that $\mathrm{S}-100 \beta$ is an important biological indicator of HIE and serum S-100 $\beta$ levels can be used as a reference index to assess HIE severity.

Key words: S- $100 \beta$ protein; Hypoxic-ischemic encephalopathy; Meta-analysis

\section{INTRODUCTION}

Hypoxic-ischemic encephalopathy (HIE) is a clinical syndrome characterized by the appearance of neurological symptoms, including a low level of consciousness, hypotonia, and difficulty in initiating and maintaining respiration. It is the leading cause of mortality and longterm morbidity in neonates worldwide (Liu et al., 2011b). HIE results from a combination of reduced perfusion and/or decreased cerebral oxygenation, resulting in debilitating disorders such as cerebral palsy, epilepsy, mental retardation, and other sensorineural impairments and disabilities (Jacobs et al., 2011). It can occur during conception or parturition, and its severity is classified as mild, moderate, and severe (Perlman and Shah, 2011). It has an incidence rate of 0.5 to 1 per 1000 infants worldwide, and the mortality rate is $20-37 \%$ for moderate HIE and $50-89 \%$ for severe HIE (Lynch et al., 2012). HIE is multifactorial in neonates and mainly involves perinatal asphyxia, and several other etiologies such as infection, uterine rupture, maternal malnutrition, cord prolapse, and placental abruption also contribute to HIE (Pimentel-Coelho et al., 2012). Studies show that $30 \%$ of moderate HIE survivors and $100 \%$ of severe HIE survivors show long-term neurological disability because clinical treatment and prevention strategies for HIE are yet to be established, indicating a significant need for focused research in this area (Kim et al., 2013; Taniguchi et al., 2014). Currently, the S-100 $\beta$ protein biomarker level is suggested as a potential reference index for the diagnosis and treatment of HIE (Douglas-Escobar et al., 2010).

The $\mathrm{S} 100$ proteins are a family of $\mathrm{Ca}^{2+}$-binding cytosolic proteins that are expressed in multiple cell types and contain 2 subunits, i.e., $\alpha$ and $\beta$; these proteins are involved in cell cycle progression, cell development, cytoskeletal-membrane interactions, and cell differentiation (McKiernan et al., 2011; Sun et al., 2012). The S-100ß is a small molecule of molecular weight $10.5 \mathrm{kDa}$ and is expressed in glial cells in the nervous system (Modi and Kanungo, 2010). It is secreted into the extracellular space, and is also found in the serum, and is believed to mediate cellular activities in an autocrine, paracrine, or endocrine manner (Marks and Allore, 1990; Patro et al., 2009). The S-100 $\beta$ exerts significant influence on cellular metabolism, $\mathrm{Ca}^{2+}$ homeostasis, cytoskeletal modification, cell proliferation, and cell differentiation, mainly by binding to synaptic proteins and inhibiting their phosphorylation (Modi and Kanungo, 2010). This protein is also associated with neurodegenerative diseases, Alzheimer's disease, Down's syndrome, apoptosis, and brain injury (Nogueira et al., 2009). Multiple studies have suggested that the serum S-100 $\beta$ concentration is an important biological indicator of HIE severity (Beharier et al., 2012; Douglas-Escobar and Weiss, 2012b). However, one study could not confirm the relationship between serum S-100 $\beta$ levels and HIE severity (Qian et al., 2009). In light of these conflicting findings, we performed a meta-analysis to investigate the association between HIE and the S-100 $\beta$ protein. 


\section{MATERIAL AND METHODS}

\section{Literature search}

A comprehensive literature search was performed to identify relevant studies published before September 2014. Accordingly, published studies reporting the association between HIE and S-100 $\beta$ protein were retrieved from the following computerized bibliographic databases: PubMed, EBSCO, Ovid, SpringerLink, Wiley, Web of Science, Wanfang, China National Knowledge Infrastructure, and VIP. The highly sensitive search terms included MeSH and Medline medical index terms and free text terms such as "hypoxia-ischemia, brain", "brain hypoxia ischemia", "hypoxic ischemic encephalopathy", "anoxic ischemic encephalopathy", "cerebral hypoxia ischemia", "anoxia ischemia, brain", or "cerebral anoxia ischemia", and each was crossed with the word "S-100ß". Additionally, cross-references of key studies were manually searched to identify additional relevant literature.

\section{Inclusion and exclusion criteria}

The following inclusion criteria were applied for selecting studies in the current meta-analysis: 1) case-control studies; 2) study subjects including HIE neonates and healthy controls; 3) English or Chinese studies; 4) studies reporting the association between HIE and S-100ß; 5) complete data available such as country, ethnicity, publication year, sample size, gestational age, gender, detection method, HIE severity, and S-100 $\beta$ expression levels. The exclusion criteria were as follows: 1) ambiguous diagnosis of study subjects; 2) duplicate publications; 3) incomplete data.

\section{Data extraction}

In order to reduce bias and enhance confidence, 2 researchers separately extracted information from the retrieved papers by using a standard data abstraction form and reached a consensus on all the items through discussion and reexamination by multiply researchers. The following relevant data were extracted from the eligible studies: surname and initials of the first author, year of submission, country, language, ethnicity, gestational age, gender, detection method, HIE severity, and S-100 $\beta$ expression levels.

\section{Statistical analysis}

Standardized mean difference (SMD) and $95 \%$ confidence interval $(95 \% \mathrm{CI})$ values were calculated for studies investigating S-100 $\beta$ expression, and the $Z$-test was performed to determine the significance of the overall effect size. This meta-analysis used Cochran's $Q$-statistic ( $\mathrm{P}<0.05$ was considered to be significant) and the $I^{2}$ test to assess heterogeneity among studies (Zintzaras and Ioannidis, 2005a). If significant heterogeneity existed $(\mathrm{P}<0.05$ or $I^{2}$ test exhibited $>50 \%$ ), a random-effect model was used; otherwise, a fixed-effect model was used (Higgins and Thompson, 2002; Zintzaras and Ioannidis, 2005b). Sensitivity analyses were performed to assess the influence of each individual study on the overall estimate, by the sequential removal of individual studies. Furthermore, we used contour-enhanced funnel plots and the Egger linear regression test to detect publication bias $(\mathrm{P}<0.05$ was considered to 
be significant). All tests were two-sided, and all statistical analyses were performed using the STATA software (version 12.0, Stata Corporation, College Station, TX, USA). A value of $\mathrm{P}<$ 0.05 was considered to be statistically significant.

\section{RESULTS}

\section{Studies included}

A total of 93 studies were initially retrieved through electronic database searches and manual searches. On the basis of the predetermined exclusion criteria, we excluded 4 studies that were duplicates, 4 studies that were letters and reviews, 22 studies that did not include human research, and 25 studies that had no relationship with our research topic. Further, 23 studies were excluded after reading the full text, and 2 studies were excluded because of a lack of highly related data. Finally, 13 case-control studies (Martins et al., 2006; Cheng et al., 2007; Murabayashi et al., 2008; Gazzolo et al., 2004, 2009; Sun et al., 2009; Jin et al., 2011; Liu et al., 2011a; Ding, 2013; Li et al., 2008, 2013; Ma et al., 2013; Nong et al., 2013), published between 2004 and 2013, were incorporated in this meta-analysis. The 13 studies included a total of 646 HIE neonates (150 mild HIE, 106 moderate HIE, and 390 severe HIE neonates) and 381 healthy controls, with sample sizes ranging from 21 to 121 . Of the 13 case-control studies, 10 included Asian subjects (specifically, 9 included Chinese subjects and 1 included Japanese subjects) and 3 included Caucasian subjects (specifically, 2 included Italian subjects and 1 included Brazilian subjects). In the studies included, enzyme-linked immunosorbent assay and radioimmunoassay were used for S-100 $\beta$ estimation. The detailed characteristics of the studies included are summarized in Table 1. In the present study, HIE severity was classified according to the clinical staging of HIE.

\begin{tabular}{|c|c|c|c|c|c|c|c|c|c|c|c|}
\hline \multirow[t]{2}{*}{ First author } & \multirow[t]{2}{*}{ Country } & \multirow[t]{2}{*}{ Ethnicity } & \multicolumn{4}{|c|}{ Gender $(\mathrm{M} / \mathrm{F})$} & \multicolumn{4}{|c|}{ Age (years) } & \multirow[t]{2}{*}{ Method } \\
\hline & & & Case & Case & Case & Control & Case & Case & Case & Control & \\
\hline Nong (2013) & China & Asians & $8 / 7$ & $7 / 4$ & $5 / 3$ & $9 / 7$ & $271.83 \pm 15.11$ & $272.05 \pm 14.00$ & $273.77 \pm 16.05$ & $273.69 \pm 13.87$ & ELISA \\
\hline Ma (2013) & China & Asians & $9 / 6$ & - & $10 / 11$ & $9 / 7$ & $271 \pm 10$ & - & $281 \pm 8$ & $287 \pm 7$ & ELISA \\
\hline $\operatorname{Li}(2013)$ & China & Asians & $10 / 11$ & $11 / 9$ & $11 / 12$ & $15 / 15$ & - & - & - & - & RIA \\
\hline Ding (2013) & China & Asians & - & - & $25 / 23$ & $13 / 12$ & - & - & $264.74 \pm 4.56$ & $266.98 \pm 5.11$ & ELISA \\
\hline Liu (2011a) & China & Asians & - & - & - & - & - & - & - & - & ELISA \\
\hline $\operatorname{Jin}(2011)$ & China & Asians & $15 / 18$ & $11 / 10$ & $9 / 12$ & $10 / 11$ & $273 \pm 11.2$ & $270.2 \pm 22.61$ & $270.2 \pm 22.61$ & $270.9 \pm 6.09$ & ELISA \\
\hline Sun (2009) & China & Asians & - & - & - & - & - & - & - & - & ELISA \\
\hline Gazzolo (2009) & Italy & Caucasians & - & - & $37 / 34$ & $25 / 23$ & - & - & - & - & ELISA \\
\hline Li (2008) & China & Asians & $72 / 32$ & & & $11 / 6$ & - & - & - & - & ELISA \\
\hline Murabayashi (2008) & Japan & Asians & - & - & - & - & - & - & - & - & ELISA \\
\hline Cheng (2007) & China & Asians & - & - & - & - & $275.8 \pm 9.1$ & & & $281.4 \pm 6.3$ & ELISA \\
\hline Martins (2006) & Brazil & Caucasians & - & - & - & - & - & - & - & - & ELISA \\
\hline Gazzolo (2004) & Italy & Caucasians & - & - & - & - & - & - & - & - & ELISA \\
\hline
\end{tabular}

$\mathrm{M}=$ male; $\mathrm{F}$ = female; ELISA = enzyme-linked immunosorbent assay; RIA = radioimmunoassay.

\section{Pooled outcome of the meta-analysis}

All 13 studies reported differences in the S-100 $\beta$ expression levels between severe HIE neonates and healthy controls. The random-effect model was used because of the heterogeneity 
of the studies included $\left(I^{2}=95 \%, \mathrm{P}<0.001\right)$. The results of our meta-analysis showed significantly higher S-100 $\beta$ expression levels in severe HIE neonates than in healthy controls $(\mathrm{SMD}=1.57,95 \% \mathrm{CI}=1.38-1.75, \mathrm{P}<0.001)$ (Figure 1A). Seven of the 13 studies reported the $\mathrm{S}-100 \beta$ expression levels in mild HIE neonates. The random-effect model was used because of the heterogeneity of these studies $\left(I^{2}=84.6 \%, \mathrm{P}<0.001\right)$. The results showed significantly higher S-100 $\beta$ expression levels in mild HIE neonates than in healthy controls (SMD $=1.42$, $95 \% \mathrm{CI}=1.15-1.69, \mathrm{P}<0.001)($ Figure $1 \mathrm{~B})$. Five studies reported differences in the $\mathrm{S}-100 \beta$ expression levels between moderate HIE neonates and healthy controls. Furthermore, the random-effect model was used because of the significant heterogeneity of these studies $\left(I^{2}\right.$ $=80.5 \%, \mathrm{P}<0.001)$. The results showed significantly higher S-100 $\beta$ expression levels in moderate HIE neonates than in healthy controls $(\mathrm{SMD}=3.08,95 \% \mathrm{CI}=2.67-3.48, \mathrm{P}<0.001)$ (Figure 1C). Seven of the 13 studies reported differences in the S-100 $\beta$ expression levels between mild and severe HIE neonates, and the random-effect model was used because of the heterogeneity of these studies $\left(I^{2}=86.0 \%, \mathrm{P}<0.001\right)$. The results showed significantly higher S-100 $\beta$ expression levels in severe HIE neonates than in mild HIE neonates (SMD $=1.97,95 \% \mathrm{CI}=1.67-2.27, \mathrm{P}<0.001$ ) (Figure 1D). Five studies reported differences in the S-100 $\beta$ expression levels between moderate and severe HIE neonates, and the random-effect model was used because of the heterogeneity of these studies $\left(I^{2}=74.2 \%, \mathrm{P}<0.001\right)$. The results showed significantly higher S-100 $\beta$ expression levels in severe HIE neonates than in moderate HIE neonates $(\mathrm{SMD}=1.16,95 \% \mathrm{CI}=0.86-1.45, \mathrm{P}<0.001)$ (Figure 1E). Five of the 13 studies reported differences in the S-100 $\beta$ expression levels between mild and moderate HIE neonates, and a fixed-effect model was used because of a lack of heterogeneity of the studies $\left(I^{2}<50 \%, \mathrm{P}=0.505\right)$. The results showed significantly higher $\mathrm{S}-100 \beta$ expression levels in moderate HIE neonates than in mild HIE neonates $(\mathrm{SMD}=1.86,95 \% \mathrm{CI}=1.54-2.17, \mathrm{P}<$ 0.001) (Figure 1F).

Subgroup analysis by ethnicity revealed significantly higher S-100 $\beta$ expression levels in severe HIE neonates than in healthy controls in both Asians and Caucasians (Asians: $\mathrm{SMD}=2.34,95 \% \mathrm{CI}=2.09-2.60, \mathrm{P}<0.001$; Caucasians: $\mathrm{SMD}=0.73,95 \% \mathrm{CI}$ $=0.47-0.10, \mathrm{P}<0.001$ ) (Figure $2 \mathrm{~A}$ ). In addition, in Asian subjects, the $\mathrm{S}-100 \beta$ expression levels were significantly higher in mild HIE neonates than in healthy controls and in severe HIE neonates than in mild HIE neonates (mild HIE $v s$ healthy controls: $\mathrm{SMD}=1.52,95 \% \mathrm{CI}$ $=1.24-1.79, \mathrm{P}<0.001$; severe $v s$ mild HIE: $\mathrm{SMD}=2.09,95 \% \mathrm{CI}=1.77-2.40, \mathrm{P}<0.001)$ (Figure 2B and C). However, in Caucasian subjects, the differences in the S-100 $\beta$ expression levels between mild HIE neonates and healthy controls and between severe and mild HIE neonates were not statistically significant (mild HIE $v s$ healthy controls: $\mathrm{SMD}=0.0,95 \% \mathrm{CI}$ $=-1.09-1.09, \mathrm{P}=1.00$; severe $v$ m mild HIE: $\mathrm{SMD}=0.59,95 \% \mathrm{CI}=-0.49-1.68, \mathrm{P}=0.284$ ) (Table 2, Figure 2B and C).

\section{Sensitivity analysis and publication bias}

The results of the sensitivity analyses showed that each individual study exerted no obvious influence on the overall effect size, i.e., the SMD (Figure 3A-F). Symmetrical contour-enhanced funnel plots and the Egger linear regression test for the differences in the S-100 $\beta$ expression levels between HIE neonates and healthy controls indicated no publication bias $(\mathrm{P}>0.05$ in all) (Figure 4A-F). 


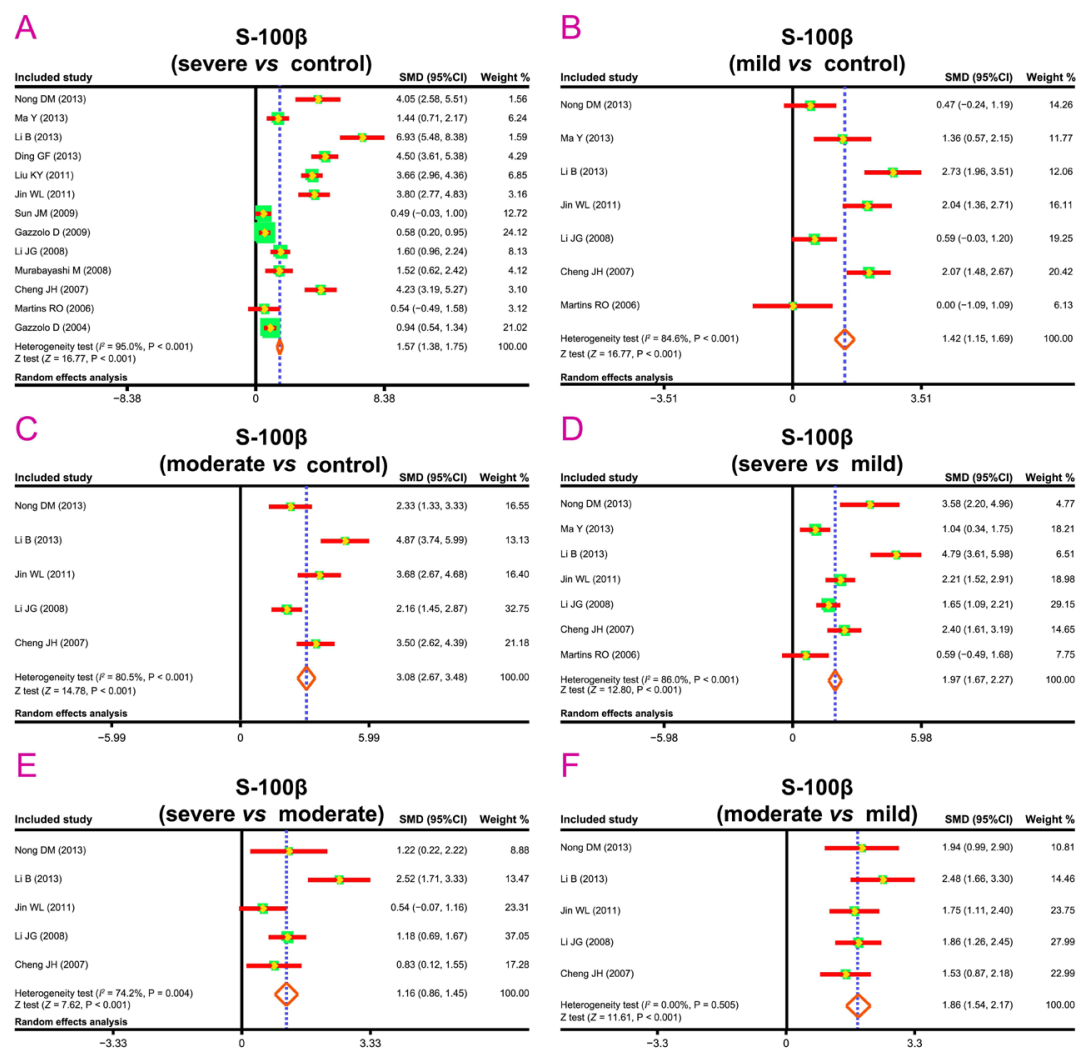

Figure 1. Forest plots of the association between HIE and S-100 $\beta$ protein. Dotted line means the equilibrium position of overall effect. SMD $=$ standard mean difference; $95 \% \mathrm{CI}=95 \%$ confidence interval.

Table 2. Expression levels of the S-100ß protein in neonates with different HIE severities.

\begin{tabular}{|c|c|c|c|c|}
\hline & & \multirow[t]{2}{*}{ Overall } & \multicolumn{2}{|c|}{ Ethnicity } \\
\hline & & & Asians & Caucasians \\
\hline \multirow[t]{3}{*}{ Severe $v s$ control } & SMD & 1.57 & 2.34 & 0.73 \\
\hline & $95 \% \mathrm{CI}$ & $1.38-1.75$ & $2.09-2.60$ & $0.47-0.10$ \\
\hline & $\mathrm{P}$ & 0.001 & 0.001 & 0.001 \\
\hline \multirow[t]{3}{*}{ Mild $v s$ control } & SMD & 1.42 & 1.52 & 0.0 \\
\hline & $95 \% \mathrm{CI}$ & $1.15-1.69$ & $1.24-1.79$ & $-1.09-1.09$ \\
\hline & $P$ & 0.001 & 0.001 & 1.00 \\
\hline \multirow{3}{*}{ Moderate $v s$ control } & SMD & 3.08 & - & - \\
\hline & $95 \% \mathrm{CI}$ & $2.67-3.48$ & - & - \\
\hline & $\mathrm{P}$ & 0.001 & - & - \\
\hline \multirow[t]{3}{*}{ Severe $v s$ mild } & SMD & 1.97 & 2.09 & 0.59 \\
\hline & $95 \% \mathrm{CI}$ & $1.67-2.27$ & $1.77-2.40$ & $-0.49-1.68$ \\
\hline & $\mathrm{P}$ & 0.001 & 0.001 & 0.284 \\
\hline \multirow[t]{3}{*}{ Severe $v s$ moderate } & SMD & 1.16 & - & - \\
\hline & $95 \% \mathrm{CI}$ & $0.86-1.45$ & - & - \\
\hline & $\mathrm{P}$ & 0.001 & - & - \\
\hline \multirow[t]{3}{*}{ Moderate $v s$ mild } & SMD & 1.86 & - & - \\
\hline & $95 \% \mathrm{CI}$ & $1.54-2.17$ & - & - \\
\hline & $P$ & 0.001 & - & - \\
\hline
\end{tabular}

$\mathrm{SMD}=$ standardized mean difference $; 95 \% \mathrm{CI}=95 \%$ confidence interval. 


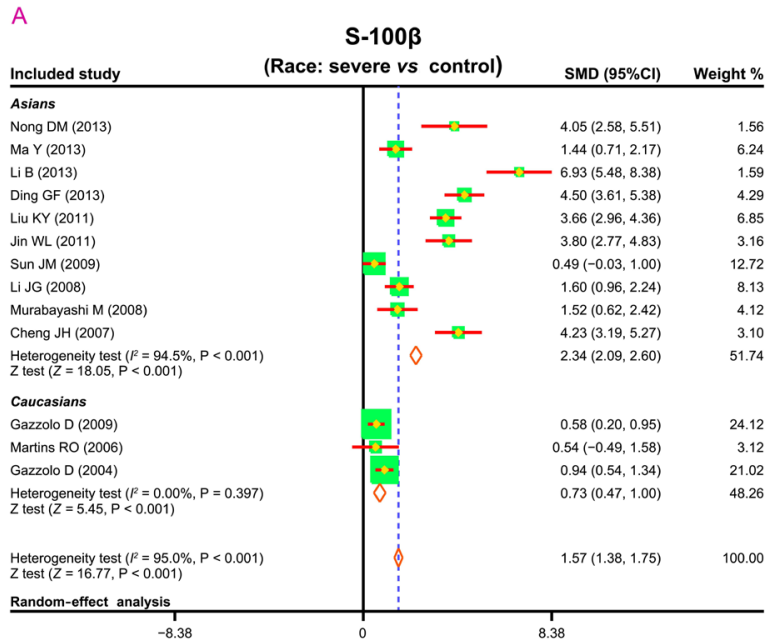

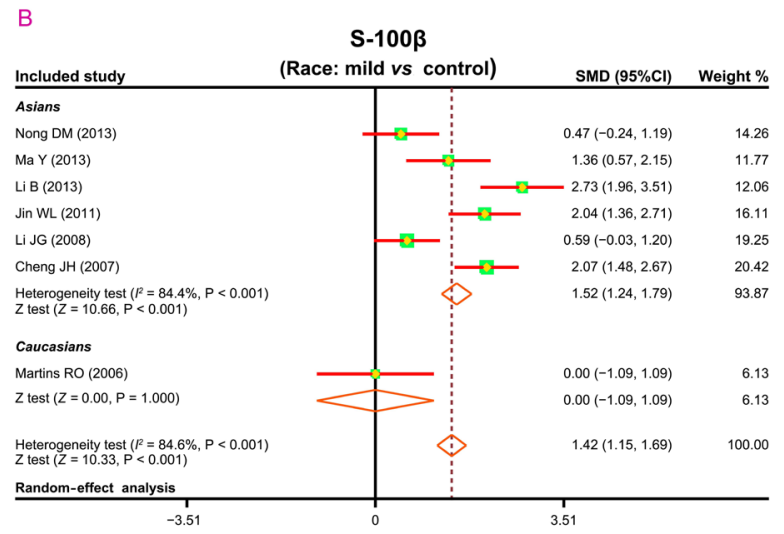

C

\begin{tabular}{|c|c|c|c|}
\hline Included study & $\begin{array}{c}S-100 \beta \\
\text { (Race: severe vs mild) }\end{array}$ & SMD $(95 \% \mathrm{Cl})$ & Weight \% \\
\hline \multicolumn{4}{|l|}{ Asians } \\
\hline Nong DM (2013) & & $3.58(2.20,4.96)$ & 4.77 \\
\hline $\operatorname{Ma} Y(2013)$ & $\rightarrow-$ & $1.04(0.34,1.75)$ & 18.21 \\
\hline Li B (2013) & & $=4.79(3.61,5.98)$ & 6.51 \\
\hline Jin WL (2011) & $\rightarrow-$ & $2.21(1.52,2.91)$ & 18.98 \\
\hline Li JG (2008) & $-\frac{\pi}{2}$ & $1.65(1.09,2.21)$ & 29.15 \\
\hline Cheng JH (2007) & $i$ & $2.40(1.61,3.19)$ & 14.65 \\
\hline $\begin{array}{l}\text { Heterogeneity test }(P=86.1 \%, P<0.001) \\
Z \text { test }(Z=13.02, P<0.001)\end{array}$ & & $2.09(1.77,2.40)$ & 92.25 \\
\hline \multicolumn{4}{|l|}{ Caucasians } \\
\hline Martins RO (2006) & -0 & $0.59(-0.49,1.68)$ & 7.75 \\
\hline$Z$ test $(Z=1.07, P=0.284)$ & & $0.59(-0.49,1.68)$ & 7.75 \\
\hline $\begin{array}{l}\text { Heterogeneity test }\left(C^{2}=86.0 \%, P<0.001\right) \\
Z \text { test }(Z=12.80, P<0.001)\end{array}$ & (i) & $1.97(1.67,2.27)$ & 100.00 \\
\hline Random-effect analysis & & & \\
\hline
\end{tabular}

Figure 2. Forest plots of the association between HIE and S-100ß protein according to subgroup analysis by race. Dotted line means the equilibrium position of overall effect. SMD $=$ standard mean difference; $95 \% \mathrm{CI}=95 \%$ confidence interval. 
A

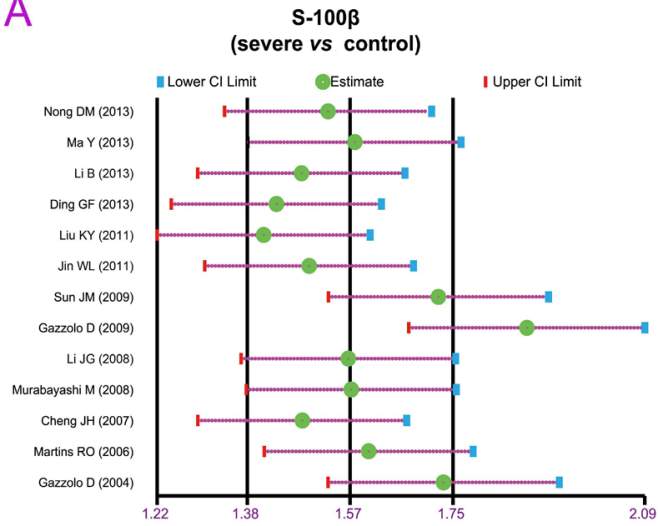

C
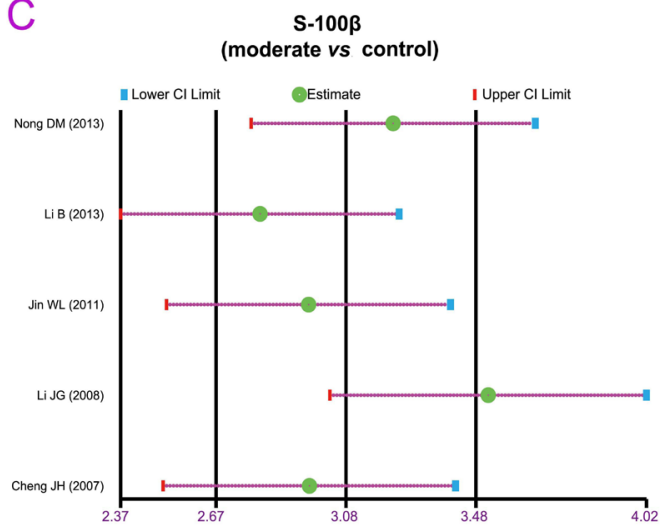

$E$
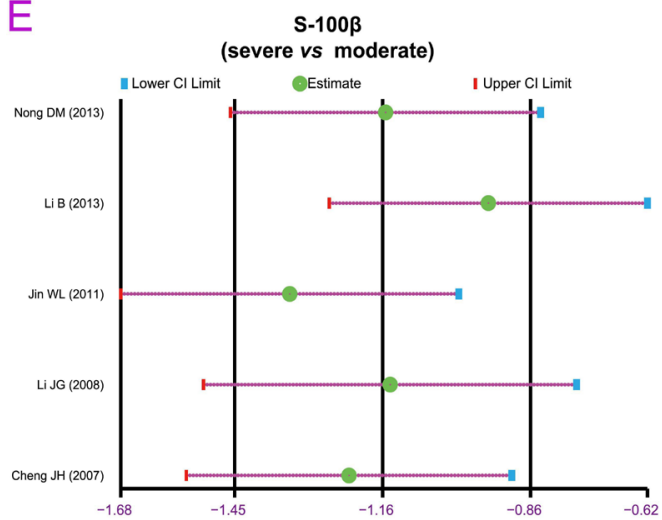

B

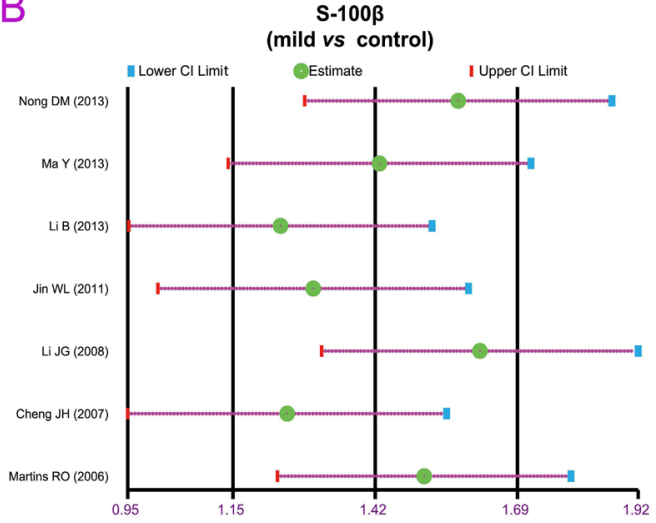

D

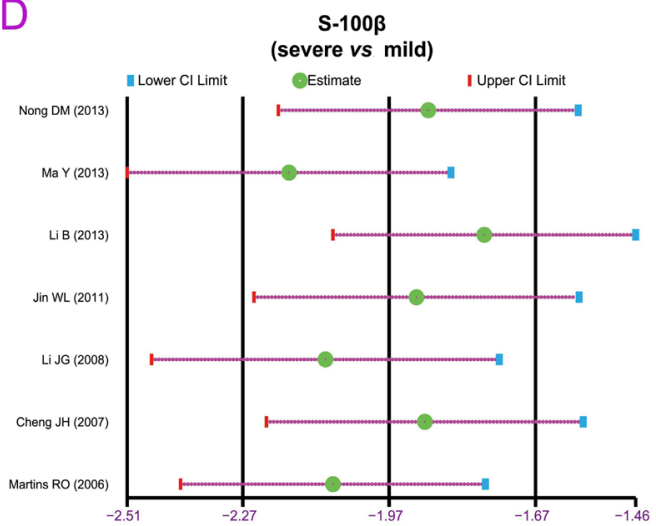

F
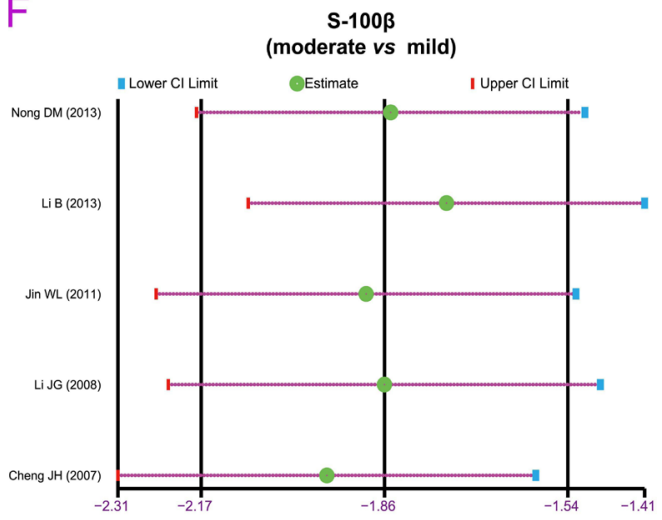

Figure 3. Sensitivity analysis of the association between HIE and S-100 $\beta$ protein. 
A

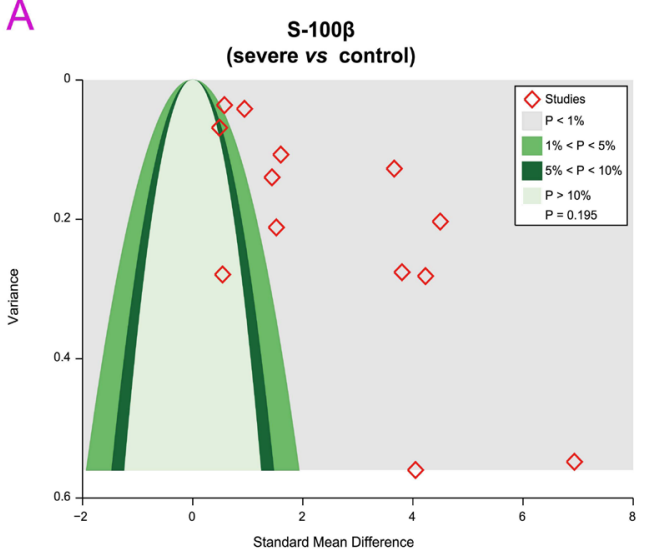

C

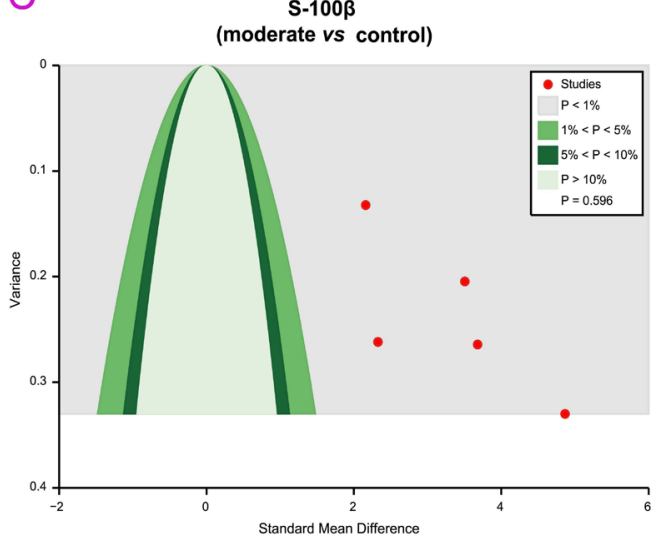

E
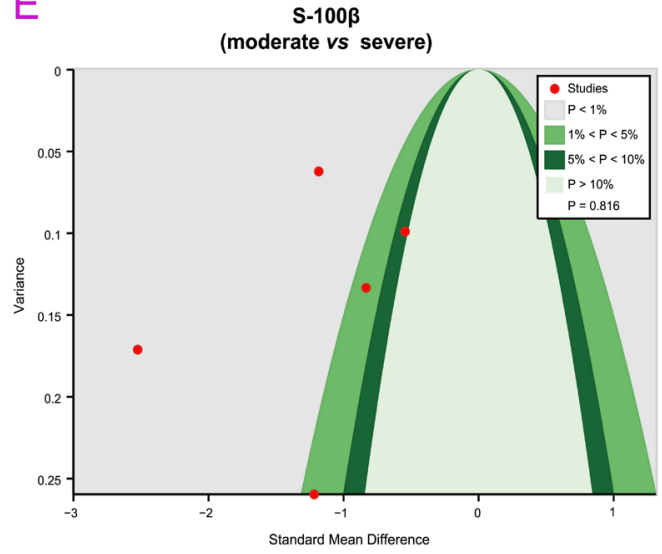

B
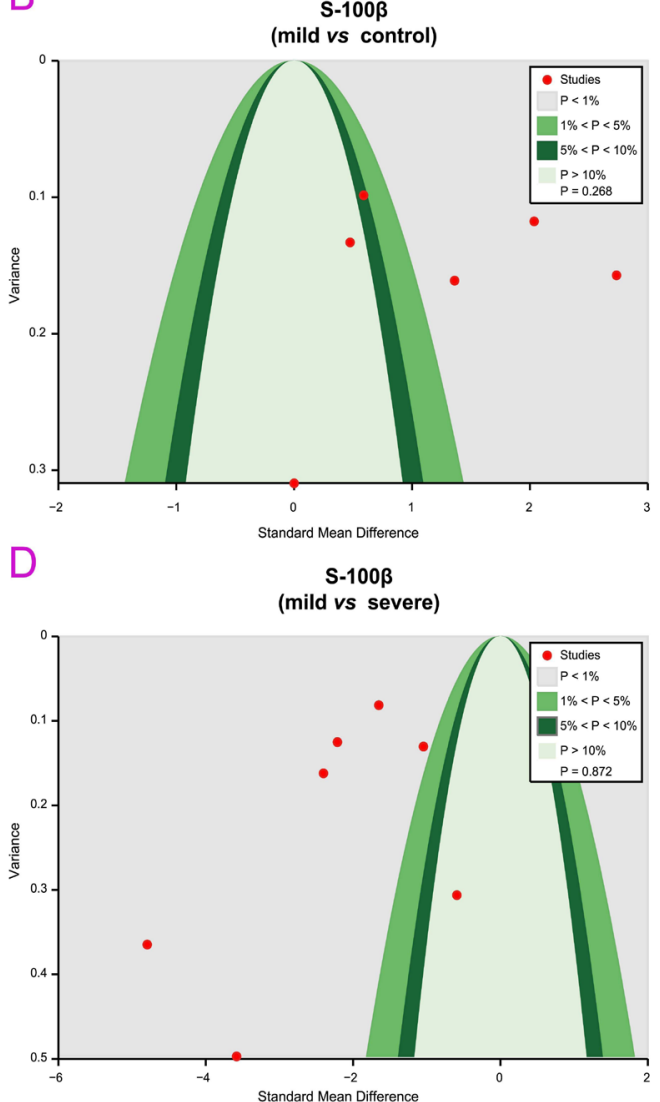

F
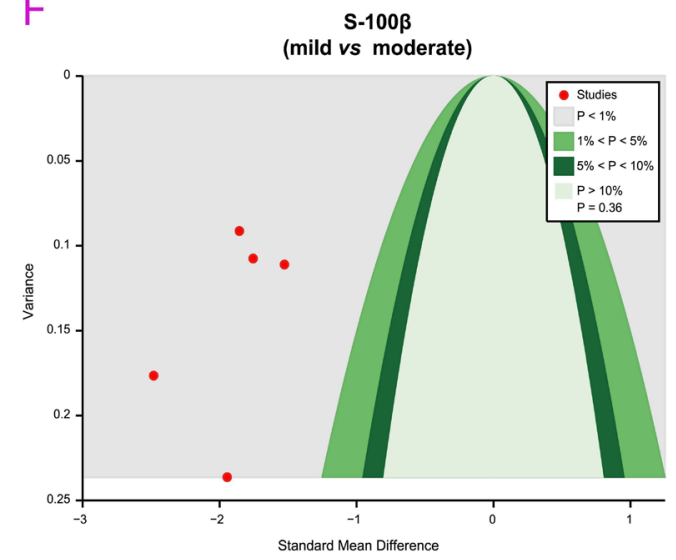

Figure 4. Publication bias assessment of the association between HIE and S-100 $\beta$ protein. 


\section{DISCUSSION}

HIE causes death in severe cases in newborn infants and frequently results in lifetime neurobehavioral and cognitive dysfunction (Beharier et al., 2012; Zalewska et al., 2015). Because reliable tools for diagnosis are currently unavailable, it is essential to thoroughly evaluate potential biomarkers and their applications in HIE settings. Using data extracted from previous studies, we performed a comprehensive meta-analysis to investigate the association between HIE and the S-100 $\beta$ protein. The main outcome of this meta-analysis is that the serum S- $100 \beta$ level is a reliable diagnostic marker for HIE, and serum S-100 $\beta$ levels can be used as a reference index to assess HIE severity. The S-100 $\beta$ protein is expressed in glial and neuronal cells (Gazzolo et al., 2010; Serpero et al., 2013). It has dual effects depending on its concentration; that is, at nanomolar concentrations, the protein is neurotrophic (Pustylnyak et al., 2011). However, when the $\mathrm{S}-100 \beta$ protein is overexpressed at micromolar concentrations, it has neurotoxic effects and increases neuroinflammation and neuronal cell apoptosis (Douglas-Escobar and Weiss, 2012a). This protein normally cannot pass through the blood-brain barrier (BBB) owing to its high molecular weight. However, in HIE, because of enhanced BBB permeability and/or compromised membrane integrity, the $\mathrm{S}-100 \beta$ protein is rapidly released into the blood stream from the injured brain, thus elevating serum S-100 $\beta$ levels (Douglas-Escobar and Weiss, 2012a; Hagberg and Ek, 2014). Therefore, higher serum S-100 $\beta$ levels are observed in HIE, and serum S-100 $\beta$ levels can be used as a reference index to determine HIE severity.

We investigated other factors that may influence the diagnostic value of S-100 $\beta$ in HIE. Accordingly, a subgroup analysis was performed by ethnicity. The results of the ethnicity-stratified analysis showed significantly higher S-100 $\beta$ expression levels in severe HIE neonates than in healthy controls. In Asians, significantly higher S-100 $\beta$ expression levels were found in moderate HIE neonates than in healthy controls, and similarly, significantly higher S-100 $\beta$ levels were found in severe HIE neonates than in moderate HIE neonates. However, there were no differences in the S-100 $\beta$ expression levels between moderate HIE neonates and healthy controls and between moderate and severe HIE neonates, which might be owing to the different geographical locations and environmental and genetic factors of different individuals in different countries.

Our study had some limitations. First, there was a lack of data on the S-100 $\beta$ expression levels in mild and moderate HIE neonates, which prospectively reduced the strength of the overall results. Second, the sample sizes of the studies included were relatively small, which may influence the application range of our results. Third, our meta-analysis included only 13 studies, which may have potentially lowered the strength of the results. Finally, the majority of the studies included involved Chinese subjects, and therefore, ethnicity bias may have affected the overall results.

In summary, our meta-analysis demonstrated that the serum S-100 $\beta$ level is an important diagnostic marker of HIE, and serum S-100 $\beta$ levels can be used as a reference index to assess HIE severity. However, because of the abovementioned limitations, further studies with larger sample sizes and better designs are required to confirm our findings on the association between HIE and the S-100 $\beta$ protein.

\section{Conflicts of interest}

The authors declare no conflict of interest. 


\title{
ACKNOWLEDGMENTS
}

\author{
Research supported by NSFC grants (\#U1204806) to L. Tian.
}

\section{REFERENCES}

Beharier O, Kahn J, Shusterman E and Sheiner E (2012). S100B - a potential biomarker for early detection of neonatal brain damage following asphyxia. J. Matern. Fetal Neonatal Med. 25: 1523-1528.

Cheng JH, Hua Y, Zhang WX and Guo H (2007). Early changes and clinical significance of serum S100b protein with hypoxic-ischemic encephalopathy. J. Gannan Med. Univ. 27: 30-31.

Ding GF (2013). S100B diagnosis of neonatal hypoxic ischemic encephalopathy and brain injury. Chin. J. Med. Guide 15: 1151-1153.

Douglas-Escobar M and Weiss MD (2012a). Biomarkers of brain injury in the premature infant. Front Neurol. 3: 185.

Douglas-Escobar M and Weiss MD (2012b). Biomarkers of hypoxic-ischemic encephalopathy in newborns. Front Neurol. 3: 144.

Douglas-Escobar M, Yang C, Bennett J, Shuster J, et al. (2010). A pilot study of novel biomarkers in neonates with hypoxic-ischemic encephalopathy. Pediatr. Res. 68: 531-536.

Gazzolo D, Marinoni E, Di Iorio R, Bruschettini M, et al. (2004). Urinary S100B protein measurements: A tool for the early identification of hypoxic-ischemic encephalopathy in asphyxiated full-term infants. Crit. Care Med. 32: 131-136.

Gazzolo D, Frigiola A, Bashir M, Iskander I, et al. (2009). Diagnostic accuracy of S100B urinary testing at birth in fullterm asphyxiated newborns to predict neonatal death. PLoS One 4: e4298.

Gazzolo D, Abella R, Frigiola A, Giamberti A, et al. (2010). Neuromarkers and unconventional biological fluids. $J$. Matern. Fetal Neonatal Med. 23: 66-69.

Hagberg H and Ek CJ (2014). Targeting the vasculature for cerebroprotection in the immature brain. Exp. Neurol. 261: 551-552.

Higgins JP and Thompson SG (2002). Quantifying heterogeneity in a meta-analysis. Stat. Med. 21: 1539-1558.

Jacobs SE, Morley CJ, Inder TE, Stewart MJ, et al. (2011). Whole-body hypothermia for term and near-term newborns with hypoxic-ischemic encephalopathy: a randomized controlled trial. Arch. Pediatr. Adolesc. Med. 165: 692-700.

Jin WL, Yu M and Li ZY (2011). Diagnostic value of serum S100B on neonatal hypoxic and ischemic encephalopathy. Chin. J. Postgraduates Med. 34: 40-41.

Kim JJ, Buchbinder N, Ammanuel S, Kim R, et al. (2013). Cost-effective therapeutic hypothermia treatment device for hypoxic ischemic encephalopathy. Med. Devices 6:1-10.

Li B, Jia CY and Shan W (2013). Clinical value of serum APN and S100B levels on neonatal hypoxic and ischemic encephalopathy. J. Radioimmunol. 26: 577-578.

Li JG, Huang Y, You JY, Wei DM, et al. (2008). The level changes and clinical research of Par-4 protein and S100b protein in serum with hypoxic ischemic encephalopathy. J. Gannan Med. Univ. 28: 808-809.

Liu KY, Zhang ZM, Wang Q, Yue QL, et al. (2011a). Diagnostic value of serum TNF- $\alpha$ and S100B in newborn infants with hypoxic-ischemic encephalopathy. Int. J. Lab. Med. 32: 875-876.

Liu X, Tooley J, Loberg EM, Suleiman MS, et al. (2011b). Immediate hypothermia reduces cardiac troponin I after hypoxic-ischemic encephalopathy in newborn pigs. Pediatr. Res. 70: 352-356.

Lynch NE, Stevenson NJ, Livingstone V, Murphy BP, et al. (2012). The temporal evolution of electrographic seizure burden in neonatal hypoxic ischemic encephalopathy. Epilepsia 53: 549-557.

Ma Y, Guo J, Zhang Y and Zhou Y (2013). Application value of serum S100B on early diagnosis of neonatal hypoxic and ischemic encephalopathy. Med. Inform. 26: 64-65.

Marks A and Allore R (1990). S100 protein and Down syndrome. Bioessays 12: 381-383.

Martins RO, Rotta NT, Portela LV and Souza DO (2006). S100B protein related neonatal hypoxia. Arq. Neuropsiquiatr. 64: 24-29.

McKiernan E, McDermott EW, Evoy D, Crown J, et al. (2011). The role of S100 genes in breast cancer progression. Tumour Biol. 32: 441-450.

Modi PK and Kanungo MS (2010). Age-dependent expression of S100beta in the brain of mice. Cell Mol. Neurobiol. 30: 709-716.

Murabayashi M, Minato M, Okuhata Y, Makimoto M, et al. (2008). Kinetics of serum S100B in newborns with intracranial lesions. Pediatr. Int. 50: 17-22.

Nogueira MI, Abbas SY, Campos LG, Allemandi W, et al. (2009). S100beta protein expression: gender- and age-related daily changes. Neurochem. Res. 34: 1355-1362. 
Nong DM, Ye XY, Qiu HY, Liang RW, et al. (2013). Changes of S100B and NSE in serum of neonates with hypoxic ischemic and observation of clinical effect intervented by FDP. Med. Inform. 664-666.

Patro N, Shrivastava M, Tripathi S and Patro IK (2009). S100beta upregulation: a possible mechanism of deltamethrin toxicity and motor coordination deficits. Neurotoxicol. Teratol. 31: 169-176.

Perlman M and Shah PS (2011). Hypoxic-ischemic encephalopathy: challenges in outcome and prediction. J. Pediatr. 158: e51-e54.

Pimentel-Coelho PM, Rosado-de-Castro PH, da Fonseca LM and Mendez-Otero R (2012). Umbilical cord blood mononuclear cell transplantation for neonatal hypoxic-ischemic encephalopathy. Pediatr. Res. 71: 464-473.

Pustylnyak VO, Lisachev PD, Shtark MB and Epstein OI (2011). Regulation of S100B gene in rat hippocampal CA1 area during long term potentiation. Brain Res. 1394: 33-39.

Qian J, Zhou D and Wang YW (2009). Umbilical artery blood S100beta protein: a tool for the early identification of neonatal hypoxic-ischemic encephalopathy. Eur. J. Pediatr. 168: 71-77.

Serpero LD, Bellissima V, Colivicchi M, Sabatini M, et al. (2013). Next generation biomarkers for brain injury. J. Matern. Fetal Neonatal Med. 26: 44-49.

Sun J, Li J, Cheng G, Sha B, et al. (2012). Effects of hypothermia on NSE and S-100 protein levels in CSF in neonates following hypoxic/ischaemic brain damage. Acta Paediatr. 101: e316-e320.

Sun JM, Jiang DL, Li CW, Zhao L, et al. (2009). Relations of S100B protein and brain injure-related indicators in neonates with hypoxic ischemic encephalopathy. Chin. J. Nuclear Med. 29: 398-400.

Taniguchi H, Anacker C, Wang Q and Andreasson K (2014). Protection by vascular prostaglandin E2 signaling in hypoxicischemic encephalopathy. Exp. Neurol. 255: 30-37.

Zalewska T, Jaworska J and Ziemka-Nalecz M (2015). Current and experimental pharmacological approaches in neonatal hypoxic-ischemic encephalopathy. Curr. Pharm. Des. 21: 1433-1439.

Zintzaras E and Ioannidis JP (2005a). HEGESMA: genome search meta-analysis and heterogeneity testing. Bioinformatics 21: 3672-3673

Zintzaras E and Ioannidis JP (2005b). Heterogeneity testing in meta-analysis of genome searches. Genet. Epidemiol. 28: 123-137. 